\section{Thoughts of an Indian psychiatrist}

I am writing in response to Professor - Srinivasa Murthy's thematic paper on international recruitment in issue 7 of International Psychiatry (January 2005, pp. 3-5). To put things in context, I am currently a specialist registrar in general adult psychiatry in the Oxford Deanery. However, I am from India and graduated from Medical College, Calcutta. After taking the MBBS and a year's internship as a pre-registration house officer (PRHO) I trained as a senior house officer (SHO) in psychiatry. I then took the test of the Professional and Linguistics and Assessment Board (PLAB) to further my training in psychiatry in the UK. The question is why, or may be even why not?

The system prevalent in India is very different to the one in the UK. In the UK after a year as a PRHO one applies for aSHO rotation in aspecialty of one's choice. However, in India there are a number of bottlenecks through which a medical student must pass. After getting through the rigorous final MBBS examination and a 1year internship, new graduates take up a house staff appointment in a discipline of their choice and simultaneously start preparing for the MD/MS entrance examination. In this medics are tested in over 21 subjects. A large majority of the questions asked have very little clinical relevance. The idea is not to test knowledge so much as to eliminate asufficient number of examinees to match the number of seats available. After this initial lottery comes a second, in which disciplines are allocated. The discipline in which one was a house staff officer or in which one was interested has hardly any bearing on what one gets. On the allocation day, if there are acouple of people ahead in the merit list interested in the discipline that one is ving for, one may say goodlbye to a prospective career. Thus, most medics begin their careers with a compromise. Aspiring physicians become surgeons, surgeons become psychiatrists and so on.

Even as a medical student I was interested in psychiatry but, as there was very little in the undergraduate course on psychiatry, I was unsure whether, in the long run, it would be the right discipline for me. In October 1999 I had just begun my placement as a house staff officer in psychiatry and within a month I knew this was what I wanted to do for the rest of my life. Now I was faced with the decision of either going through the lottery (examination) conducted by the Medical Council of India or coming to the UK and applying for psychiatry
SHO rotations. Needless to say, I took the much easier second option.

There are only a couple of institutes in India, the National Institute of Mental Health and Neuroscience (NIMHANS) and that at Kanke, which conduct examinations specifically for aspiring psychiatrists by induding a paper or a certain percentage of questionson psychiatry. However, seats are very limited; NIMHANS, the institute to which Professor Murthy belongs, had six seats in the general category in 1999 and there would have been literally thousands of people competing for these. Thus the trip to the UK is a choice that many aspiring psychiatrists in India are making.

Fierce competition is not the only reason that causes would-be psychiatrists to travel to the UK. Resources are another big issue. India, like any other developing nation, is still fighting with major killers such as malaria, tuberculosis, typhoid and cholera. When it comes to healthcare investment, psychiatry is very low on the list This scarcity of resources has an obvious effect on training. Since I have not helped in anyway with resources by coming to the UK, it would be inappropriate for me to complain about this. None the less, I could contribute to the human resources for mental healthcare in India in the near future, after gaining the Certificate of Completion of Specialist Training(CCST). However, every time I see a psychiatrist who has an MD from India but who is still applying for $\mathrm{SHO}$ jobs in the UK, I find myself pondering why he or she is here - for further training an easy life, higher pay, frustration with the Indian private sector or government setting, or perhaps a combination of these factors?

The bottom line is that, when I came to the UK, I wanted to complete the College Membership examination and CCST and go back to India, where I hoped to make a difference with the knowledge that I would acquire. In all fairness this resolve has weakened and is getting weaker every day. Being in Oxford, I have had the opportunity to work with some of the 'big names' in psychiatry. My own interest is in the genetics and neuroimaging of schizophrenia and I would like to go into full-time research. I know that would be the end of my dream to return to India. I have put off making the decision but I do not know for how long I will be able to delay. Either way I will have regrets.

Manaan Kar Ray Specialist Registrar (General Adult Psychiatry), Warneford Hospital, Oxford OX3 7JX, UK, email manaan.ray@psych.ox.ac.uk
Correspondence is welcome on any of the articles or issues raised in

International Psychiatry. Letters of no more than 500 words should be sent to the Editor, Hamid Ghodse, email hghodse@ sghms.ac.uk 